\title{
Ethnic Variations in Diagnosis, Treatment, Socioeconomic Status and Survival in a Large Population-Based Cohort of Elderly Patients with Non-Hodgkin's Lymphoma
}

\author{
Michael Wang, MD , Keith D. Burau, $\mathrm{PhD}^{2}$, Shenying Fang, MD, $\mathbf{M S}^{3}$, Harry Wang, $\mathrm{PhD}^{4}$, \\ and Xianglin L. Du, MD, PhD $^{3}$ \\ ${ }^{1}$ Department of Lymphoma and Myeloma, University of Texas M. D. Anderson Cancer Center, \\ Houston, Texas. \\ ${ }^{2}$ Division of Biostatistics, University of Texas School of Public Health, Houston, Texas. \\ ${ }^{3}$ Division of Epidemiology, University of Texas School of Public Health, Houston, Texas. \\ ${ }^{4}$ Department of Family and Community Medicine, Baylor College of Medicine, Houston, Texas.
}

\section{Abstract}

Background: There is a lack of research on ethnic disparities in survival among patients with Non-Hodgkin's Lymphoma (NHL), although these disparities have been documented for patients with many other tumors.

Methods: A retrospective cohort of 13,321 patients diagnosed with incident NHL at age $>=65$ in 1992-1999, were identified from the SEER (Surveillance, Epidemiology and End Results)Medicare linked database with 11 years of follow-up. Of these patients, 11,868 were Caucasians, 533 were African-Americans, and 920 were other ethnicities. A time-to-event Cox regression model was used to examine the relative risk of all-cause and disease-specific mortality.

Results: A larger proportion (72.2\%) of African-Americans were in the poorest quartile of socioeconomic status as measured by the poverty level compared to $21.8 \%$ of Caucasians, and $43.2 \%$ of African-Americans received chemotherapy compared to $52.4 \%$ of Caucasians ( $<<0.01$ ). Hazard ratio of all-cause and NHL-specific mortality increased significantly with age, advanced stage, higher comorbidity scores, and poorer socioeconomic status. Patients receiving either chemotherapy or radiotherapy or both were significantly less likely to die. After taking into account of differences in treatment, comorbidity, and socioeconomic status, there was no statistically significant difference in the risk of all-cause (Hazard ratio $=0.97,95 \%$ confidence interval: $0.88-1.08)$ and disease-specific mortality (1.07, 0.92-1.25) between African-Americans and Caucasians.

Conclusions: The risk of mortality in patients with NH-lymphoma was associated with socioeconomic status and was reduced in patients receiving chemotherapy. No significant differences in the risk of mortality were observed between African-Americans and Caucasians after controlling for factors such as treatment and socioeconomic status.

Correspondence to: Xianglin L. Du, MD, PhD, University of Texas School of Public Health, 1200 Herman Pressler Drive, Houston, TX 77030. Fax: (713)5009264; Xianglin.L.Du@uth.tmc.edu. 


\section{Condensed abstract}

The risk of mortality in patients with NH-lymphoma was associated with socioeconomic status and was reduced in patients receiving chemotherapy. No significant differences in the risk of mortality were observed between African-American and Caucasian patients after controlling for factors such as treatment and socioeconomic status.

\section{Keywords}

Non-Hodgkin's lymphoma; chemotherapy; socioeconomic status; racial disparity; survival

\section{Introduction}

Non-Hodgkin's Lymphoma (NHL) is a common tumor in the elderly population with median age at diagnosis of 67 years. ${ }^{1,2}$ It is estimated that over 63,000 men and women will be diagnosed with NHL each year and about 18,660 men and women will die of NHL with a median age at death of 74 years in the United States. ${ }^{1,2}$ The incidence of NHL has been increasing over the last several decades worldwide,,${ }^{1-7}$ and Caucasians have higher incidence and mortality rates of NHL than patients in other ethnic groups. ${ }^{1,2,5}$ During this period of time, treatment has improved, particularly with combination chemotherapy CHOP (cyclophosphamide, doxorubicin, vincristine, and prednisone) ${ }^{8-16}$ and later with the addition of Rituximab to CHOP for B cell NHL since $1998 .{ }^{17-20}$ Although there were several studies that demonstrated ethnic disparities in receiving these treatments, ${ }^{21-23}$ none of these studies has specifically addressed ethnic disparities in survival, and whether these survival differences were due to disparities in treatment, diagnosis, socioeconomic status or other factors in patients with NHL.

\section{Patients and Methods}

\section{Data Sources}

This study used the SEER (Surveillance, Epidemiology and End Results)-Medicare linked data for patients diagnosed in 1992-1999. The method of linking these data has been described elsewhere. ${ }^{24,25}$ The SEER program, supported by the National Cancer Institute, consists of population-based tumor registries that collect standardized information on all cancers diagnosed within the specified geographic regions. ${ }^{24-27}$ The metropolitan areas of San Francisco/Oakland, Detroit, Atlanta, and Seattle; Los Angeles County; the San JoseMonterey area; and the states of Connecticut, Iowa, New Mexico, Utah, and Hawaii were included in this report. The Medicare component, on the other hand, is the primary health insurer for the great majority of the U.S. population $\geq 65$ years of age. It covers hospital, physician, and other medical services for $>97 \%$ of persons age $\ 65$ years. ${ }^{24,25}$ The Committee for Protection of Human Subjects at the University of Texas Health Science Center at Houston approved this study. 


\section{Study Population}

The retrospective cohort consisted of 13,570 patients diagnosed with incident NHL at age $\checkmark 65$ in 1992-1999, and identified from the SEER-Medicare linked database. The 249 cases were excluded with missing information on socioeconomic status, leaving 13321 subjects in the final analysis. Of 13,321, 11,868 were Caucasians (non-Hispanic), 533 were AfricanAmericans (non-Hispanic), and 920 were other ethnicities.

\section{Study Variables}

Survival variables-The vital status, cause of death, and date of death in SEER data were obtained from the National Center for Health Statistics by National Cancer Institute. ${ }^{27}$ Survival time in months was calculated from the date of diagnosis to the date of death or date of last follow-up (December 31, 2002). All-cause mortality was defined if patients died of any cause that was the underlying cause of death. Patients still alive at the last date of follow-up were censored. NHL-specific mortality was defined if lymphoma was the underlying cause of death, in which patients who died of causes other than lymphoma were censored.

Socioeconomic status-Three variables from the 1990 census available in the SEERMedicare linked data were used to define socioeconomic status at the census tract level and were categorized into quartiles: a) education - percent of adults aged $\geq 25$ who had less than 12 years of education: first ( $₫ \%$ - $10.89 \%$ ), second $(10.91 \%-17.94 \%)$, third $(17.95 \%$ $-25.80 \%$ ), and fourth quartile ( $\geq 25.81 \%$ ); b) poverty - percent of persons living below the poverty line: first ( $3.70 \%)$, second $(3.71 \%-6.89 \%)$, third (6.90\%-11.98\%), and fourth quartile ( $>11.99 \%$ ); c) income - median annual household income (in U.S. dollars): first ( $\geq$ $\$ 45,427)$, second $(\$ 35,178-45,424)$, third $(\$ 26,894-35,174)$, and fourth quartile ( $\$ 26,882)$. In addition, a composite socioeconomic variable combining these three variables with equal weights was created and categorized into quartiles. ${ }^{28}$

Chemotherapy-Information on chemotherapy was identified from Medicare claims, which was described elsewhere. ${ }^{29,30}$ In brief, the following Medicare claim codes were used for defining chemotherapy: International Classification of Disease (ICD)-9-CM procedure code 9925 for injection or infusion of cancer chemotherapeutic substance, the Common Procedure Terminology codes 96400-96549, J8510, J8520, J8521, J8530-J8999, J9000J9999, and Q0083-Q0085 for chemotherapy administration, revenue center codes 0331 (chemotherapy injected), 0332 (chemotherapy oral), and 0335 (chemotherapy intravenous), and the ICD-9-CM V codes of V58.1, V66.2, or V67.2 for follow up examination or care after chemotherapy. Because only $23(0.2 \%)$ patients received stem cell transplantation (ICD-9-CM codes of 4100-4109, or CPT codes of 38230, 38231, 38240, or 38241) 31,32 within 12 months of diagnosis, this variable was not included in the final analysis.

Radiation Therapy-Since the information on radiation therapy from SEER and Medicare complement each other, ${ }^{33}$ cases were defined as having received radiation therapy if SEER data or Medicare claims data indicated so. 
Tumor Factors-Tumor stage as defined in the SEER Extension of Disease (EOD)-88 ( $3^{\text {rd }}$ edition $)^{27}$ was included. The Ann Arbor staging system was used and reported as follows: Stage I (involvement of a single lymph node region, or localized involvement of a single extralymphatic organ or site); Stage II (involvement of two or more lymph node regions on the same side of the diaphragm, or localized involvement of a single extralymphatic organ or site and its regional lymph nodes on the same side of the diaphragm with or without involvement of other lymph node regions on the same side of the diaphragm); Stage III (involvement of lymph node regions on both sides of the diaphragm, with or without localized involvement of an extralymphatic organ or site or spleen involvement); Stage IV (disseminated or multifocal involvement of one or more extralymphatic organs); and unknown stage. The Extent of Disease codes from SEER data were: stage 1=00-17, $2=20$ $29,3=30-78,4=80-90$, and unstaged $=99$. Because of heterogeneities of different histologic subtypes of NHL, analysis was stratified by several major types of NHL according to the methods by Morton and colleagues: ${ }^{5,34,35}$ diffuse large B-cell lymphoma (histology codes of 9675,9678-9684), chronic lymphocytic leukemia (9670), follicular lymphoma (9690-9698), and all other subtypes or unknown.

Comorbidity Scores-Comorbidity was ascertained from Medicare claims data through diagnoses or procedures made 1 year before and 1 month after the diagnosis of NHL. The Medicare inpatient, outpatient, and physician claims were used to create a comorbidity score. The detailed method has been discussed elsewhere. ${ }^{36}$ The rationale for including diagnoses from the physician claims was that many more patients saw a physician rather than being hospitalized, thus increasing the possibility of identifying more comorbid conditions. ${ }^{36}$ This score reflects the Deyo adaptation of the Charlson comorbidity index, ${ }^{37,38}$ with several procedure codes that reflect the Romano adaptation. ${ }^{39}$ The comorbidity score was then categorized into: $0,1,2$, or $\geq 3$.

Other Characteristics-Other characteristics obtained from the SEER data include age at diagnosis, race/ethnicity, marital status, year of diagnosis, geographic area, tumor stage, and nodal site. Tumor variables were well-validated in SEER registries, ${ }^{24,25}$ and so was the information on marital status, year of diagnosis and geographic area. Although race/ethnicity categories may have involved a certain degree of misclassification, two categories (AfricanAmerican and Caucasian) in this study are likely to have a minimal misclassification bias, if any. ${ }^{40}$

\section{Analysis}

The differences in the distribution of baseline characteristics among the three ethnic groups were tested using the chi-square statistic. Cox proportional hazard regression model was used for analysis of survival using the PHREG procedure in SAS. ${ }^{41}$ The proportionality assumption was considered to be satisfied when the log-log Kaplan-Meier curves for survival functions by race/ethnicity or SES were parallel and did not intersect. The median survival time in months was obtained from the LIFETEST procedure that is based on the Kaplan-Meier method. The interaction between race/ethnicity and SES was tested using the product term of these two variables in the model. Variables that were adjusted for in the 
model include age, sex, race, tumor stage, nodal site, radiation, comorbidity score, geographic area, and year of diagnosis.

\section{Results}

Table 1 presents the distribution of patient demographic and tumor characteristics across the ethnic groups of patients with NH-lymphoma. A higher proportion of cases were diagnosed at age 65-69 in African-Americans (24.8\%) and in other ethnic groups (22.4\%) than in Caucasians (19.5\%). The mean age was 76 years for Caucasians, 74 for African-Americans and 75 for others. There were slightly more female patients than males, and a larger proportion (58.2\%) of African-American patients were unmarried. A slightly greater proportion of cases was diagnosed at an early stage and had a lower Comorbidity score in Caucasians and other ethnic groups than that in African-Americans. The percentage of patients receiving chemotherapy and radiation therapy was lower in African-Americans. For example, $43.2 \%$ of African-Americans received chemotherapy compared to $52.4 \%$ of Caucasians and $54.7 \%$ of others ( $\mathrm{p}<0.001)$. Similarly, $18.2 \%$ of African-Americans received radiation therapy compared to $24.3 \%$ of Caucasians and $26.6 \%$ of others ( $\mathrm{p}<0.001)$. The proportion of cases was stable over ten years among these three ethnic groups.

Table 2 presents the distribution of socioeconomic status among the three racial/ethnic groups of patients. A larger proportion of African-Americans were in the poorest quartiles of education, poverty, income, and composite socioeconomic status compared to that of Caucasians. For example, $72.2 \%$ of African-Americans and 38.7\% of others were in the poorest quartile of socioeconomic status as measured by the poverty level compared to $21.8 \%$ of Caucasians $(\mathrm{p}<0.001)$. The differences in these factors in Tables 1 and 2 between Caucasians and African-Americans were all statistically significant except for sex and year of diagnosis. The tests for trend across ethnic groups by age, socioeconomic status, comorbidity, and year of diagnosis were statistically significant at $\mathrm{p}<0.01$ but not for stage $(\mathrm{p}=0.425)$.

Table 3 presents the 1, 3 and 5-year observed survival rates by racial/ethnic groups and socioeconomic status, stratified by tumor stage. Since the last date of follow-up in Medicare was December 2002, all cases in our study cohort had been followed for at least 3 years. The 3-year observed survival for stage I-II from all-causes was 55.8\% in Caucasians, $52.6 \%$ in African-Americans, and $44.7 \%$ in others. Survival increased with higher socioeconomic status. For example, the 3-year observed survival was 59.9\% in subjects who lived in the community with highest quartile of composite socioeconomic status, and $48.8 \%$ in those with lowest quartile. This survival pattern in association with race/ethnicity and socioeconomic status was similar at the 1 and 5-year level and for NHL-specific survival (Table 3). Median survival time was 32.5 months (95\% confidence interval: 31.0-34.8) for patients receiving chemotherapy and 11.9 months (95\% confidence interval: 1.4-1.8) for those who did not receive chemotherapy.

Table 4 presents the percentage of patients receiving chemotherapy and radiation therapy by stage, ethnicity and socioeconomic status, and the odds ratio of receiving these therapies while controlling for other confounding factors such as age, sex, marital status, comorbidity, 
year of diagnosis and SEER regions. For patients with both early stage (I-II) and late stage (III-IV), African-American patients were significantly less likely to receive chemotherapy (odds ratio $=0.69,95 \% \mathrm{CI}=0.50-0.95$ for stage I-II) and other ethnic groups were slightly more likely but not significantly to receive this therapy (odds ratio $=1.16,95 \% \mathrm{CI}=0.92-$ 1.47) compared to Caucasians. However, there were no significant differences in receiving radiation therapy among these ethnic groups. There were also no significant variations by socioeconomic status.

Table 5 presents the effects of patient and tumor factors on the risk of all-cause and NHLspecific mortality in association with race/ethnicity for all populations and stratified by stage I-II and stage III-IV. Compared to Caucasians, African-Americans did not have statistically significant risks of all-cause (Hazard ratio $=0.97,95 \%$ confidence interval: $0.88-1.08$ for all stages) and disease-specific mortality $(1.07,0.92-1.25)$, whereas other ethnic patients with stage I-II were significantly more likely to die of all-cause $(1.28,1.12-1.46)$ and of NHLspecific mortality $(1.43,1.15-1.78)$, after adjusting for treatment, comorbidity and socioeconomic factors. Women were significantly less likely to die than men while the opposite was the case for unmarried patients compared to married ones. The hazard ratio of all-cause and disease-specific mortality increased significantly with age $(\mathrm{P}<0.001)$. The hazard ratio also increased with advanced tumor stage, higher comorbidity scores, and poorer socioeconomic status. Overall, patients receiving either chemotherapy or radiation therapy or both were significantly less likely to die of all-causes.

When stratified by subtypes of NHL, the results were similar (Table 6). For example, racial disparities in both all-cause and NHL-specific mortality were not significant across diffuse large B-cell lymphoma, chronic lymphocytic leukemia or small lymphocytic lymphoma, follicular lymphoma, and all other subtypes.

\section{Discussion}

This study examined racial/ethnic disparities in diagnosis, treatment and socioeconomic factors in association with survival in patients with $\mathrm{NH}$-lymphoma. Our study revealed several important findings. First, it indicates that $52.4 \%$ of elderly Caucasian patients with NHL received chemotherapy compared to $43.2 \%$ of African-Americans $(\mathrm{P}<0.01)$. Second, although chemotherapy has been documented to be efficacious in prolonging survival in clinical trial settings, few community-based studies demonstrated its effectiveness. Our study of this large population-based cohort indicates that the receipt of chemotherapy was significantly associated with prolonged survival in patients with NHL. Third, there were substantial variations in socioeconomic status within this cohort of patients, with a larger proportion of African-American patients living in the lowest or poorest quartile of socioeconomic status. Poor socioeconomic status was significantly associated with increased risk of mortality. Finally, ethnic disparities at diagnosis, treatment and socioeconomic status played a major role in survival disparities. After adequately controlling for these factors in the analysis, there were no significant differences in all-cause and NHL-specific mortality between African-American and Caucasian patients. 
With advances in medical care, particularly with effective chemotherapy, patients with NHL can now live much longer. This survival benefit documented in numerous clinical trials ${ }^{8-20}$ has been translated into the community effectiveness according to our population-based study. Those patients receiving chemotherapy had a significantly lower risk of death. However, substantial disparities in receiving these therapies were observed among ethnic groups with a particularly lower rate of chemotherapy and radiation therapy in AfricanAmerican patients. Furthermore, there was a strong relationship between the risk of mortality and socioeconomic status, while a larger proportion of elderly African-American patients lived in communities with poorer socioeconomic status. Therefore, controlling for socioeconomic factor in the analysis was important when examining racial disparities in survival. This study was the first to show ethnic survival disparity in patients with NHL.

Our study also indicated that other ethnic groups had a slightly higher risk of all-cause and disease-specific death that was limited in patients with stage I-II lymphoma. However, because other ethnic groups had small numbers of cases and included numerous different ethnic populations, the results would be more vulnerable to residual confounding due to imperfect adjustment for differences in these populations. Our study also found that women with NHL were significantly less likely to die of all causes for all stages and to die of lymphoma specifically for stages I-II only, even after adjustment for other factors. This finding was consistent with reports from the SEER registries with a higher relative survival in women than in men. ${ }^{1,2}$

This study has a number of strengths. First, this SEER-Medicare linked data not only provided well-validated information on tumor characteristics at diagnosis and 11 years of follow-up of the vital status, but also allowed the examination of socioeconomic status at the census tract level. Second, our study cohort of elderly patients was covered by Medicare insurance program regardless of where they received care in the country. Thus, more complete information on cancer therapy were obtained by Medicare claims. In addition, comorbid conditions can well be identified from Medicare data. Since comorbidity is a known factor associated with treatment and survival, controlling for comorbidity in analysis is important to minimize residual confounding when addressing ethnic disparities in survival.

It is also important to note several limitations of this study. First, only Medicare beneficiaries with fee-for-service for Part A and Part B coverage and without HMO enrollment were selected in the analysis because Medicare data does not include claims for HMO enrollees. There were potential selection biases here if those beneficiaries excluded had different characteristics or patterns of care among ethnic groups. As a result, the generalizability of the results to other populations could be affected. In addition, the study findings may not be generalizable to population of less than 65 year old. Furthermore, this database does not have detailed clinical information on lymphoma grade which may form the basis on which chemotherapy and radiation therapy may be recommended. Therefore, appropriateness of these therapies cannot be assessed adequately from these existing Medicare claims data. Furthermore, there are numerous histologic subtypes of NHL, but some subtypes may not be reliably differentiated. For example, agreement between cancer registry data and chart coders was $90 \%$ for diffuse large B-cell lymphoma and $89 \%$ for 
follicular lymphoma, but only $52 \%$ for mantle cell lymphoma. ${ }^{35}$ Therefore, certain groupings may be helpful to reduce misclassification bias. ${ }^{34,35}$ Our analysis was stratified by several major subtypes of NHL. Finally, since patients were diagnosed with NH lymphoma in 1992-1999 and their treatments were followed to 2002, the use of newly approved chemotherapy agents was unknown, including rituximab that was approved for treating NHL at the end of 1997. Further studies including cases diagnosed in more recent years would help to address the effect of these new chemotherapy agents.

In conclusion, there was a strong positive association between the use of chemotherapy and prolonged survival, and poorer socioeconomic status was significantly associated with the higher risk of mortality. There were no significant differences in all-cause and lymphomaspecific mortality between African-American and Caucasian patients with Non-Hodgkin's lymphoma after controlling for treatment, socioeconomic status and patient demographics and tumor factors. It would be helpful if further studies incorporate patients' clinical performance status and disease severity.

\section{Acknowledgements}

We acknowledge the efforts of the National Cancer Institute; Center for Medicare and Medicaid Services; Information Management Services, Inc.; and the SEER Program tumor registries in the creation of this database. Dr. Du is supported in part by a grant from the Agency for Healthcare Research and Quality (R01-HS016743).

\section{References}

1. National Cancer Institute. Cancer Stat Fact Sheets http://seer.cancer.gov/statfacts/html/nhl.html. (Accessed February 11, 2008).

2. American Cancer Society. Cancer Facts \& Figures 2007 http://www.cancer.org/downloads/STT/ CAFF2007PWSecured.pdf. (Accessed February 11, 2008).

3. Zheng T, Mayne ST, Boyle P, et al. Epidemiology of non-Hodgkin lymphoma in Connecticut, 19351988. Cancer 1992;70:840-849. [PubMed: 1643616]

4. Groves FD, Linet MS, Travis LB, et al. Cancer surveillance series: non-Hodgkin's lymphoma incidence by histologic subtype in the United States from 1978 through 1995. J Natl Cancer Inst 2000;92:1240-1251. [PubMed: 10922409]

5. Morton LM, Wang SS, Devesa SS, et al. Lymphoma incidence patterns by WHO subtype in the United States, 1992-2001. Blood 2006;107:265-76. [PubMed: 16150940]

6. Gurney KA, Cartwright RA. Increasing incidence and descriptive epidemiology of extranodal nonHodgkin lymphoma in parts of England and Wales. Hematol J 2002;3:95-104. [PubMed: 12032871]

7. Abdel-Fattah MM, Yassine OG. Non-Hodgkin's lymphomas in Alexandria, Egypt; incidence rates and trend study (1995-2004). Eur J Cancer Prev 2007;16:479-85. [PubMed: 17923821]

8. Tirelli U, Errante D, Van GM, et al. CHOP is the standard regimen in patients $>=70$ years of age with intermediate-grade and high-grade non-Hodgkin's lymphoma: results of a randomized study of the European Organization for Research and Treatment of Cancer Lymphoma Cooperative Study Group. J Clin Oncol 1998;16:27-34. [PubMed: 9440719]

9. Miller TP, Dahlberg S, Cassady JR, et al. Chemotherapy alone compared with chemotherapy plus radiotherapy for localized intermediate- and high-grade non-Hodgkin's lymphoma. N Engl J Med 1998;339:21-26. [PubMed: 9647875]

10. Fisher RI, Gaynor ER, Dahlberg S, et al. Comparison of a standard regimen (CHOP) with three intensive chemotherapy regimens for advanced non-Hodgkin's lymphoma. N Engl J Med 1993;328:1002-1006. [PubMed: 7680764] 
11. Lichtman SM, Kolitz J, Budman DR, et al. Treatment of aggressive non-Hodgkin's lymphoma in elderly patients with thiotepa, Novantrone (mitoxantrone), vincristine, prednisone (TNOP). Am J Clin Oncol 2001;24:360-362. [PubMed: 11474261]

12. Osby E, Hagberg H, Kvaloy S, et al. CHOP is superior to CNOP in elderly patients with aggressive lymphoma while outcome is unaffected by filgrastim treatment: results of a Nordic Lymphoma Group randomized trial. Blood 2003;101:3840-3848. [PubMed: 12531794]

13. Feugier P, Van Hoof A, Sebban C, et al. Long-term results of the R-CHOP study in the treatment of elderly patients with diffuse large B-cell lymphoma: a study by the Groupe d'Etude des Lymphomes de l'Adulte. J Clin Oncol 2005;23:4117-26. [PubMed: 15867204]

14. Fisher RI, LeBlanc M, Press OW, et al. New treatment options have changed the survival of patients with follicular lymphoma. J Clin Oncol 2005;23:8447-52. [PubMed: 16230674]

15. Liu Q, Fayad L, Cabanillas F, et al. Improvement of overall and failure-free survival in stage IV follicular lymphoma: 25 years of treatment experience at The University of Texas M.D. Anderson Cancer Center. J Clin Oncol 2006;24:1582-9. [PubMed: 16575009]

16. Forstpointner R, Dreyling M, Repp R, et al. The addition of rituximab to a combination of fludarabine, cyclophosphamide, mitoxantrone (FCM) significantly increases the response rate and prolongs survival as compared with FCM alone in patients with relapsed and refractory follicular and mantle cell lymphomas: results of a prospective randomized study of the German Low-Grade Lymphoma Study Group. Blood 2004;104:3064-71. [PubMed: 15284112]

17. Swenson WT, Wooldridge JE, Lynch CF, et al. Improved survival of follicular lymphoma patients in the United States. J Clin Oncol 2005;23:5019-5026. [PubMed: 15983392]

18. Peters FP, Fickers MM, Erdkamp FL, et al. The effect of optimal treatment on elderly patients with aggressive non-Hodgkin's lymphoma: more patients treated with unaffected response rates. Ann Hematol 2001;80:406-410. [PubMed: 11529466]

19. Coiffier B, Lepage E, Briere J, et al. CHOP chemotherapy plus rituximab compared with CHOP alone in elderly patients with diffuse large-B-cell lymphoma. N Engl J Med 2002;346:235-242. [PubMed: 11807147]

20. Morrison VA. Non-Hodgkin's lymphoma in the elderly. Part 2: treatment of diffuse aggressive lymphomas. Oncology (Williston Park) 2007;21:1191-8. [PubMed: 17926798]

21. Grann VR, Hershman D, Jacobson JS, et al. Outcomes and diffusion of doxorubicin-based chemotherapy among elderly patients with aggressive non-Hodgkin lymphoma. Cancer 2006;107:1530-41. [PubMed: 16933332]

22. Cronin DP, Harlan LC, Clegg LX, et al. Patterns of care in a population-based random sample of patients diagnosed with non-Hodgkin's lymphoma. Hematol Oncol 2005;23:73-81. [PubMed: 16170828]

23. Berrios-Rivera JP, et al. Variations in Chemotherapy and Radiation Therapy in a Large Nationwide and Community-Based Cohort of Elderly Patients with Non-Hodgkin's Lymphoma. Am J Clin Oncol 2007;30:163-171. [PubMed: 17414466]

24. Potosky AL, Riley GF, Lubitz JD, et al. Potential for cancer related health services research using a linked Medicare-tumor registry database. Med Care 1993;31:732-748. [PubMed: 8336512]

25. Warren JL, Klabunde CN, Schrag D, et al. Overview of the SEER-Medicare data: content, research applications, and generalizability to the United States elderly population. Med Care 2002;40:IV18.

26. Zippin C, Lum D, Hankey BF. Completeness of hospital cancer case reporting from the SEER Program of the National Cancer Institute. Cancer 1995;76:2343-2350. [PubMed: 8635041]

27. National Cancer Institute. SEER Data Reporting Tools http://seer.cancer.gov/analysis/ (Accessed February 13, 2008).

28. Du XL, et al. Variation in modes of chemotherapy administration for breast carcinoma and association with hospitalization for chemotherapy-related toxicity. Cancer 2005;104:913-924. [PubMed: 15991239]

29. Du XL, Goodwin JS. Patterns of use of chemotherapy for breast cancer in older women: Findings from Medicare claims data. J Clin Oncol 2001;19:1455-1461. [PubMed: 11230491]

30. Warren JL, Harlan LC, Fahey A, et al. Utility of the SEER-Medicare data to identify chemotherapy use. Med Care 2002;40:IV-61. 
31. US Public Health Services. International Classification of Diseases, 9th Revision, Clinical Modification, 5th ed. Los Angeles: Practice Management Information Corporation; 1996.

32. Health Care Financing Administration. HCFA Common Procedure Coding System (HCPCS): National Level-II Medicare Codes Los Angeles: Practice Management Information Corp; 1994.

33. Du XL, Freeman JL, Goodwin JS. Information on radiation treatment in patients with breast cancer: the advantages of the linked medicare and SEER data. J Clin Epidemiol 1999;52:463-470. [PubMed: 10360342]

34. Clarke CA, Glaser SL, Dorfman RF, et al. Expert review of non-Hodgkin's lymphomas in a population-based cancer registry: reliability of diagnosis and subtype classifications. Cancer Epidemiol Biomarkers Prev 2004;13:138-43. [PubMed: 14744745]

35. Clarke CA, Undurraga DM, Harasty PJ, et al. Changes in cancer registry coding for lymphoma subtypes: reliability over time and relevance for surveillance and study. Cancer Epidemiol Biomarkers Prev 2006;15:630-8. [PubMed: 16614102]

36. Klabunde CN, Potosky AL, Legler JM, et al. Development of a comorbidity index using physician claims data. J Clin Epidemiol 2000;53:1258-1267. [PubMed: 11146273]

37. Charlson ME, Pompei P, Ales KL, et al. A new method of classifying prognostic comorbidity in longitudinal studies: development and validation. J Chronic Dis 1987; 40:373-83. [PubMed: 3558716]

38. Deyo RA, Cherkin DC, Ciol MA. Adapting a clinical comorbidity index for use with ICD-9-CM administrative databases. J Clin Epidemiol 1992;45:613-9. [PubMed: 1607900]

39. Romano PS, Roos LL, Jollis JG. Adapting a clinical comorbidity index for use with ICD-9-CM administrative data: differing perspectives. J Clin Epidemiol 1993;46:1075-9. [PubMed: 8410092]

40. Bach PB, Guadagnoli E, Schrag D, et al. Patient demographic and socioeconomic characteristics in the SEER-Medicare database applications and limitations. Med Care 2002;40(8 Suppl):IV-19-25.

41. Allison PD. Survival Analysis Using the SAS System: A Practical Guide Cary, NC: SAS Institute Inc., 1995. 
Table 1.

Comparison of characteristics among different ethnic groups in patients with NH-lymphoma

\begin{tabular}{|c|c|c|c|c|c|c|c|}
\hline \multirow[t]{2}{*}{ Characteristics } & \multicolumn{2}{|c|}{ Caucasians } & \multicolumn{2}{|c|}{ African-Americans } & \multicolumn{2}{|c|}{ Others } & \multirow{2}{*}{$\begin{array}{c}\text { P value } \\
\text { by ethnicity }\end{array}$} \\
\hline & $\mathbf{N}$ & $\%$ & $\mathbf{n}$ & $\%$ & $\mathbf{n}$ & $\%$ & \\
\hline Median age (range) & \multicolumn{2}{|c|}{$76(65-104)$} & \multicolumn{2}{|c|}{$74(65-100)$} & \multicolumn{2}{|c|}{$75(65-100)$} & \\
\hline \multicolumn{8}{|l|}{ Age } \\
\hline $65-69$ & 2319 & 19.5 & 132 & 24.8 & 206 & 22.4 & $<0.001$ \\
\hline $70-74$ & 2939 & 24.8 & 153 & 28.7 & 221 & 24.0 & \\
\hline $75-79$ & 2864 & 24.1 & 112 & 21.0 & 224 & 24.4 & \\
\hline 280 & 3746 & 31.6 & 136 & 25.5 & 269 & 29.2 & \\
\hline \multicolumn{8}{|l|}{ Sex } \\
\hline Male & 5375 & 45.3 & 228 & 42.8 & 459 & 49.9 & 0.011 \\
\hline Female & 6493 & 54.7 & 305 & 57.2 & 461 & 50.1 & \\
\hline \multicolumn{8}{|l|}{ Marital Status } \\
\hline Married & 6458 & 54.4 & 200 & 37.5 & 530 & 57.6 & $<0.001$ \\
\hline Unmarried & 4927 & 41.5 & 310 & 58.2 & 355 & 35.6 & \\
\hline Missing & 483 & 4.1 & 23 & 4.3 & 35 & 3.8 & \\
\hline \multicolumn{8}{|l|}{ Tumor Stage } \\
\hline I & 3623 & 30.5 & 121 & 22.7 & 282 & 30.7 & $<0.001$ \\
\hline II & 1700 & 14.3 & 69 & 13.0 & 150 & 16.3 & \\
\hline III & 1437 & 12.1 & 93 & 17.5 & 130 & 14.1 & \\
\hline IV & 3981 & 33.5 & 204 & 38.3 & 279 & 30.3 & \\
\hline Unknown & 1127 & 9.5 & 46 & 8.6 & 79 & 8.6 & \\
\hline \multicolumn{8}{|l|}{ Lymph node site } \\
\hline Nodal & 3585 & 30.2 & 166 & 31.1 & 388 & 42.2 & $<0.001$ \\
\hline Extranodal & 8283 & 69.8 & 367 & 68.9 & 532 & 57.8 & \\
\hline \multicolumn{8}{|l|}{ Chemotherapy } \\
\hline No & 5648 & 47.6 & 303 & 56.9 & 417 & 45.3 & $<0.001$ \\
\hline Yes & 6220 & 52.4 & 230 & 43.2 & 503 & 54.7 & \\
\hline \multicolumn{8}{|l|}{ Radiation therapy } \\
\hline No & 8985 & 75.7 & 436 & 81.8 & 675 & 73.4 & 0.001 \\
\hline Yes & 2883 & 24.3 & 97 & 18.2 & 245 & 26.6 & \\
\hline \multicolumn{8}{|l|}{ Comorbidity score } \\
\hline 0 & 6273 & 52.9 & 228 & 42.8 & 463 & 50.3 & $<0.001$ \\
\hline 1 & 3173 & 26.7 & 144 & 27.0 & 254 & 27.6 & \\
\hline 2 & 1384 & 11.7 & 73 & 13.7 & 105 & 11.4 & \\
\hline$>=3$ & 1038 & 8.8 & 88 & 16.5 & 98 & 10.7 & \\
\hline \multicolumn{8}{|l|}{ Year of diagnosis } \\
\hline 1992 & 1409 & 11.9 & 63 & 11.8 & 106 & 11.5 & 0.105 \\
\hline 1993 & 1493 & 12.6 & 61 & 11.4 & 102 & 11.1 & \\
\hline 1994 & 1480 & 12.5 & 60 & 11.3 & 108 & 11.7 & \\
\hline 1995 & 1448 & 12.2 & 70 & 13.1 & 96 & 10.4 & \\
\hline
\end{tabular}




\begin{tabular}{|c|c|c|c|c|c|c|c|c|}
\hline \multirow{3}{*}{\multicolumn{2}{|c|}{ Characteristics }} & \multicolumn{2}{|c|}{ Caucasians } & \multicolumn{2}{|c|}{ African-Americans } & \multicolumn{2}{|c|}{ Others } & \multirow{2}{*}{$\begin{array}{c}\text { P value } \\
\text { by ethnicity }\end{array}$} \\
\hline & & $\mathbf{N}$ & $\%$ & $\mathbf{n}$ & $\%$ & $\mathbf{n}$ & $\%$ & \\
\hline & & 1563 & 13.2 & 62 & 11.6 & 114 & 12.4 & \\
\hline 으 & 1997 & 1526 & 12.9 & 85 & 16.0 & 116 & 12.6 & \\
\hline 3 & 1998 & 1458 & 12.3 & 67 & 12.6 & 134 & 14.6 & \\
\hline$\frac{U}{5}$ & 1999 & 1491 & 12.6 & 65 & 12.2 & 144 & 15.7 & \\
\hline$\overline{c 0}$ & Total & 11868 & 100.0 & 533 & 100.0 & 920 & 100.0 & \\
\hline
\end{tabular}


Table 2.

Comparison of socioeconomic status among different racial/ethnic groups in patients with NH-lymphoma

\begin{tabular}{|c|c|c|c|c|c|c|}
\hline \multirow[t]{2}{*}{ Socioeconomic Status (quartile from high to low) } & \multicolumn{2}{|c|}{ Caucasians } & \multicolumn{2}{|c|}{ African-Americans } & \multicolumn{2}{|c|}{ Others } \\
\hline & $\mathbf{n}$ & $\%$ & $\mathbf{n}$ & $\%$ & $\mathbf{n}$ & $\%$ \\
\hline \multicolumn{7}{|l|}{ Education } \\
\hline $1^{\mathrm{st}}$ & 3153 & 26.6 & 32 & 6.0 & 143 & 15.5 \\
\hline $2^{\text {nd }}$ & 3101 & 26.1 & 57 & 10.7 & 175 & 19.0 \\
\hline $3^{\text {rd }}$ & 3052 & 25.7 & 80 & 15.0 & 197 & 21.4 \\
\hline $4^{\text {th }}$ & 2562 & 21.6 & 364 & 68.3 & 405 & 44.0 \\
\hline \multicolumn{7}{|l|}{ Poverty } \\
\hline $1^{\text {st }}$ & 3149 & 26.5 & 22 & 4.1 & 153 & 16.6 \\
\hline $2^{\text {nd }}$ & 3087 & 26.0 & 59 & 11.1 & 200 & 21.7 \\
\hline $3^{\text {rd }}$ & 3040 & 25.6 & 67 & 12.6 & 211 & 22.9 \\
\hline $4^{\text {th }}$ & 2592 & 21.8 & 385 & 72.2 & 356 & 38.7 \\
\hline \multicolumn{7}{|l|}{ Income } \\
\hline $1^{\mathrm{st}}$ & 3078 & 25.9 & 34 & 6.4 & 217 & 23.6 \\
\hline $2^{\text {nd }}$ & 3034 & 25.6 & 70 & 13.1 & 228 & 24.8 \\
\hline $3^{\text {rd }}$ & 2979 & 25.1 & 121 & 22.7 & 232 & 25.2 \\
\hline $4^{\text {th }}$ & 2777 & 23.4 & 308 & 57.8 & 243 & 26.4 \\
\hline \multicolumn{7}{|l|}{ Composite Socioeconomic Status } \\
\hline $1^{\text {st }}$ & 3128 & 26.4 & 31 & 5.8 & 170 & 18.5 \\
\hline $2^{\text {nd }}$ & 3116 & 26.3 & 47 & 8.8 & 169 & 18.4 \\
\hline $3^{\text {rd }}$ & 3023 & 25.5 & 80 & 15.0 & 226 & 24.6 \\
\hline $4^{\text {th }}$ & 2601 & 21.9 & 375 & 70.4 & 355 & 38.6 \\
\hline Total & 11868 & 100.0 & 533 & 100.0 & 920 & 100.0 \\
\hline
\end{tabular}


Table 3.

All-cause and lymphoma-specific survival in patients with NHL, by tumor stage, race/ethnicity and socioeconomic status

\begin{tabular}{|c|c|c|c|c|c|c|}
\hline \multirow[t]{2}{*}{ Race/ethnicity and socioeconomic status } & \multicolumn{2}{|c|}{$\begin{array}{l}\text { 1-year survival }(\%) \\
\text { (cases in 1992-1999) } \\
\quad(n=13321)\end{array}$} & \multicolumn{2}{|c|}{$\begin{array}{c}\text { 3-year survival }(\%) \\
\text { (cases in 1992-1999) } \\
(\mathrm{n}=13321)\end{array}$} & \multicolumn{2}{|c|}{$\begin{array}{c}\text { 5-year survival }(\%) \\
\text { (cases in 1992-1997) } \\
(\mathrm{n}=9962)\end{array}$} \\
\hline & All-cause & NHL-specific & All-cause & NHL-specific & All-cause & NHL-specific \\
\hline \multicolumn{7}{|c|}{ Tumor Stage I-II } \\
\hline \multicolumn{7}{|l|}{ Racial/Ethnic Groups } \\
\hline Caucasians & 72.0 & 84.4 & 55.8 & 77.1 & 44.6 & 68.9 \\
\hline African-Americans & 68.4 & 84.7 & 52.6 & 77.9 & 36.2 & 68.1 \\
\hline Others & 63.2 & 78.7 & 44.7 & 73.8 & 35.7 & 61.6 \\
\hline \multicolumn{7}{|l|}{ Socioeconomic Status (quartile) } \\
\hline $1^{\text {st }}$ (high) & 75.6 & 86.2 & 59.9 & 79.5 & 50.1 & 70.9 \\
\hline $2^{\text {nd }}$ & 72.3 & 84.3 & 56.2 & 76.9 & 44.6 & 69.2 \\
\hline $3^{\text {rd }}$ & 70.9 & 84.4 & 54.3 & 76.4 & 42.7 & 67.8 \\
\hline $4^{\text {th }}($ Low $)$ & 65.8 & 81.0 & 48.8 & 74.6 & 37.0 & 65.6 \\
\hline Patients with stage I-II & 71.2 & 84.0 & 54.9 & 76.9 & 43.7 & 68.4 \\
\hline \multicolumn{7}{|c|}{ Tumor Stage III-IV } \\
\hline \multicolumn{7}{|l|}{ Racial/Ethnic Groups } \\
\hline Caucasians & 54.6 & 71.8 & 36.3 & 63.5 & 25.4 & 52.2 \\
\hline African-Americans & 43.8 & 66.0 & 27.3 & 56.9 & 21.2 & 48.2 \\
\hline Others & 50.9 & 69.7 & 34.5 & 61.9 & 22.9 & 50.2 \\
\hline \multicolumn{7}{|l|}{ Socioeconomic Status (quartile) } \\
\hline $1^{\text {st }}$ (high) & 58.8 & 74.9 & 40.3 & 66.3 & 28.5 & 55.6 \\
\hline $2^{\text {nd }}$ & 55.5 & 72.5 & 38.0 & 65.0 & 28.2 & 54.4 \\
\hline $3^{\text {rd }}$ & 51.5 & 68.3 & 33.6 & 59.7 & 22.8 & 47.2 \\
\hline $4^{\text {th }}($ Low $)$ & 49.7 & 69.8 & 31.3 & 61.2 & 20.9 & 50.4 \\
\hline Patients with stage III-IV & 53.8 & 71.3 & 35.7 & 63.0 & 25.0 & 51.9 \\
\hline \multicolumn{7}{|c|}{ All Tumor Stages } \\
\hline \multicolumn{7}{|l|}{ Racial/Ethnic Groups } \\
\hline Caucasians & 62.3 & 77.6 & 45.3 & 70.0 & 34.4 & 60.3 \\
\hline African-Americans & 54.0 & 73.4 & 37.7 & 65.1 & 27.9 & 55.6 \\
\hline Others & 56.6 & 74.6 & 39.5 & 68.3 & 29.3 & 56.7 \\
\hline \multicolumn{7}{|l|}{ Socioeconomic Status (quartile) } \\
\hline $1^{\text {st }}($ high $)$ & 66.8 & 80.7 & 49.6 & 73.0 & 38.8 & 63.3 \\
\hline $2^{\text {nd }}$ & 63.0 & 77.8 & 46.6 & 70.6 & 36.5 & 61.9 \\
\hline $3^{\text {rd }}$ & 59.8 & 75.8 & 43.1 & 67.9 & 32.2 & 57.3 \\
\hline $4^{\text {th }}($ Low $)$ & 56.9 & 74.8 & 39.1 & 67.1 & 27.7 & 56.9 \\
\hline
\end{tabular}




\begin{tabular}{lcccccc}
\hline Race/ethnicity and socioeconomic status & $\begin{array}{c}\text { 1-year survival }(\%) \\
(\text { cases in 1992-1999) } \\
(\mathbf{n = 1 3 3 2 1})\end{array}$ & $\begin{array}{c}\text { 3-year survival (\%) } \\
(\text { cases in 1992-1999) } \\
(\mathbf{n}=13321)\end{array}$ & $\begin{array}{c}\text { 5-year survival }(\%) \\
(\text { cases in 1992-1997) } \\
(\mathbf{n}=9962)\end{array}$ \\
\cline { 2 - 7 } & All-cause & NHL-specific & All-cause & NHL-specific & All-cause & NHL-specific \\
\hline Patients with all stages & 61.6 & 77.2 & 44.6 & 69.7 & 33.8 & 59.8 \\
\hline
\end{tabular}


Table 4.

Receipt of chemotherapy and radiation therapy in patients with NH-lymphoma, by stage, race/ethnicity, and socioeconomic status

\begin{tabular}{|c|c|c|c|c|c|}
\hline \multirow[t]{2}{*}{ Race and Socioeconomic Status, and Stage } & \multirow{2}{*}{$\begin{array}{l}\text { Number of patients } \\
(\mathrm{n}=13321)\end{array}$} & \multicolumn{2}{|c|}{ Receipt of Chemotherapy } & \multicolumn{2}{|c|}{ Receipt of Radiotherapy } \\
\hline & & $\%$ & Odds ratio $*(95 \% \mathrm{CI})$ & $\%$ & Odds ratio ${ }^{*}(95 \% \mathrm{CI})$ \\
\hline \multicolumn{6}{|c|}{ Stage I-II } \\
\hline \multicolumn{6}{|l|}{ Racial/Ethnic Groups } \\
\hline Caucasians & 5323 & 50.9 & 1.00 & 35.4 & 1.00 \\
\hline African-Americans & 190 & 40.0 & $0.69(0.50-0.95)$ & 25.3 & $0.72(0.50-1.02)$ \\
\hline Others & 432 & 49.5 & $1.16(0.92-1.47)$ & 39.6 & $1.13(0.89-1.44)$ \\
\hline \multicolumn{6}{|l|}{ Socioeconomic Status (quartile) } \\
\hline $1^{\text {st }}($ high $)$ & 1554 & 51.1 & 1.00 & 36.5 & 1.00 \\
\hline $2^{\text {nd }}$ & 1476 & 48.4 & $0.93(0.80-1.09)$ & 37.7 & $1.02(0.87-1.18)$ \\
\hline $3^{\text {rd }}$ & 1482 & 52.2 & $1.07(0.92-1.26)$ & 35.8 & $0.88(0.75-1.04)$ \\
\hline $4^{\text {th }}($ low $)$ & 1433 & 50.2 & $0.98(0.83-1.15)$ & 31.1 & $0.75(0.63-0.89)$ \\
\hline \multicolumn{6}{|l|}{ Stage } \\
\hline I & 4026 & 45.4 & 1.00 & 39.8 & 1.00 \\
\hline II & 1919 & 61.2 & $1.79(1.59-2.02)$ & 26.0 & $0.54(0.48-0.61)$ \\
\hline Subtotal & 5945 & 50.5 & - & 35.3 & - \\
\hline
\end{tabular}

Stage III-IV

Racial/Ethnic Groups

\begin{tabular}{|c|c|c|c|c|c|}
\hline Caucasians & 5418 & 57.1 & 1.00 & 15.3 & 1.00 \\
\hline African-Americans & 297 & 46.8 & $0.66(0.51-0.86)$ & 14.1 & $0.85(0.59-1.22)$ \\
\hline Others & 409 & 62.1 & $1.47(1.15-1.88)$ & 15.2 & $0.88(0.64-1.22)$ \\
\hline \multicolumn{6}{|c|}{ Socioeconomic Status (quartile) } \\
\hline $1^{\text {st }}$ (high) & 1491 & 56.1 & 1.00 & 16.4 & 1.00 \\
\hline $2^{\text {nd }}$ & 1544 & 58.5 & $1.13(0.97-1.31)$ & 15.7 & $0.96(0.79-1.18)$ \\
\hline $3^{\text {rd }}$ & 1519 & 56.8 & $1.06(0.91-1.25)$ & 14.2 & $0.90(0.72-1.11)$ \\
\hline $4^{\text {th }}($ low $)$ & 1570 & 56.5 & $1.10(0.93-1.30)$ & 14.8 & $0.96(0.77-1.19)$ \\
\hline \multicolumn{6}{|l|}{ Stage } \\
\hline III & 1660 & 59.7 & 1.00 & 11.4 & 1.00 \\
\hline IV & 4464 & 56.0 & $0.86(0.76-0.97)$ & 16.7 & $1.45(1.22-1.73)$ \\
\hline Subtotal & 6124 & & - & 15.3 & - \\
\hline \multicolumn{6}{|c|}{ All Stages } \\
\hline \multicolumn{6}{|l|}{ Racial/Ethnic Groups } \\
\hline Caucasians & 11868 & 52.4 & 1.00 & 24.3 & 1.00 \\
\hline African-Americans & 533 & 43.2 & $0.68(0.56-0.83)$ & 18.2 & $0.79(0.62-1.00)$ \\
\hline Others & 920 & 54.7 & $1.32(1.12-1.55)$ & 26.6 & $1.02(0.85-1.23)$ \\
\hline
\end{tabular}

Socioeconomic Status (quartile) 


\begin{tabular}{|c|c|c|c|c|c|}
\hline \multirow[t]{2}{*}{ Race and Socioeconomic Status, and Stage } & \multirow{2}{*}{$\begin{array}{l}\text { Number of patients } \\
(\mathrm{n}=13321)\end{array}$} & \multicolumn{2}{|c|}{ Receipt of Chemotherapy } & \multicolumn{2}{|c|}{ Receipt of Radiotherapy } \\
\hline & & $\%$ & Odds ratio $^{*}(95 \% \mathrm{CI})$ & $\%$ & Odds ratio $^{*}(95 \% \mathrm{CI})$ \\
\hline $1^{\text {st }}$ (high) & 3329 & 52.4 & 1.00 & 25.9 & 1.00 \\
\hline $2^{\text {nd }}$ & 3332 & 52.3 & $1.04(0.94-1.15)$ & 25.4 & $0.98(0.87-1.10)$ \\
\hline $3^{\text {rd }}$ & 3329 & 52.7 & $1.08(0.97-1.20)$ & 23.8 & $0.90(0.79-1.01)$ \\
\hline $4^{\text {th }}($ low $)$ & 3331 & 51.6 & $1.04(0.93-1.16)$ & 21.9 & $0.84(0.74-0.95)$ \\
\hline \multicolumn{6}{|l|}{ Stage } \\
\hline I & 4026 & 45.4 & 1.00 & 39.8 & 1.00 \\
\hline II & 1919 & 61.2 & $1.81(1.61-2.03)$ & 26.0 & $0.57(0.51-0.65)$ \\
\hline III & 1660 & 59.7 & $1.61(1.42-1.82)$ & 11.4 & $0.23(0.20-0.27)$ \\
\hline IV & 4464 & 56.0 & $1.39(1.26-1.52)$ & 16.7 & $0.35(0.32-0.39)$ \\
\hline Unstaged & 1252 & 37.0 & $0.74(0.65-0.85)$ & 15.1 & $0.31(0.26-0.36)$ \\
\hline Total & 13321 & 52.2 & - & 24.2 & - \\
\hline
\end{tabular}

Odds ratio adjusted for sex, age, marital status, socioeconomic status, stage, site, comorbidity, year of diagnosis, and SEER region. 
Table 5.

All-cause and NH-Lymphoma-specific mortality in association with race/ethnicity and other factors in patients with NH-Lymphoma, stratified by stage

\begin{tabular}{|c|c|c|c|c|c|c|}
\hline \multirow{3}{*}{$\begin{array}{l}\text { Race/ethnicity and other } \\
\text { factors }\end{array}$} & \multicolumn{6}{|c|}{ Hazard ratio ( $95 \%$ confidence interval) of mortality ${ }^{\dagger}$} \\
\hline & \multicolumn{3}{|c|}{ All-cause mortality } & \multicolumn{3}{|c|}{ NH-Lymphoma-specific mortality } \\
\hline & Stage I-II & Stage III-IV & All stages & Stage I-II & Stage III-IV & All stages \\
\hline \multicolumn{7}{|l|}{ Race/ethnicity } \\
\hline Caucasians & 1.00 & 1.00 & 1.00 & 1.00 & 1.00 & 1.00 \\
\hline African-Americans & $0.90(0.75-1.08)$ & $1.07(0.93-1.22)$ & $0.97(0.88-1.08)$ & $0.84(0.62-1.14)$ & $1.17(0.96-1.41)$ & $1.07(0.92-1.25)$ \\
\hline Others & $1.28(1.12-1.46)$ & $1.02(0.90-1.17)$ & $1.13(1.03-1.23)$ & $1.43(1.15-1.78)$ & $1.08(0.90-1.30)$ & $1.19(1.04-1.36)$ \\
\hline \multicolumn{7}{|l|}{ Sex } \\
\hline Male & 1.00 & 1.00 & 1.00 & 1.00 & 1.00 & 1.00 \\
\hline Female & $0.78(0.73-0.84)$ & $0.83(0.78-0.88)$ & $0.80(0.77-0.84)$ & $0.83(0.74-0.93)$ & $0.94(0.86-1.02)$ & $0.91(0.85-0.97)$ \\
\hline \multicolumn{7}{|l|}{ Age } \\
\hline $65-69$ & 1.00 & 1.00 & 1.00 & 1.00 & 1.00 & 1.00 \\
\hline $70-74$ & $1.29(1.16-1.43)$ & $1.23(1.12-1.34)$ & $1.26(1.18-1.35)$ & $1.22(1.03-1.45)$ & $1.22(1.08-1.39)$ & $1.23(1.12-1.36)$ \\
\hline $75-79$ & $1.63(1.47-1.81)$ & $1.52(1.39-1.66)$ & $1.59(1.49-1.70)$ & $1.48(1.25-1.75)$ & $1.41(1.24-1.61)$ & $1.46(1.32-1.61)$ \\
\hline 280 & $2.66(2.41-2.94)$ & $2.07(1.90-2.26)$ & $2.39(2.25-2.55)$ & $2.18(1.86-2.56)$ & $1.91(1.69-2.160$ & $2.09(1.90-2.29)$ \\
\hline \multicolumn{7}{|l|}{ Marital status } \\
\hline Married & 1.00 & 1.00 & 1.00 & 1.00 & 1.00 & 1.00 \\
\hline Unmarried & $1.21(1.12-1.30)$ & $1.17(1.10-1.25)$ & $1.20(1.15-1.26)$ & $1.25(1.12-1.41)$ & $1.09(1.00-1.20)$ & $1.18(110-1.26)$ \\
\hline Unknown & $0.94(0.78-1.14)$ & $0.67(0.57-0.80)$ & $0.73(0.65-0.81)$ & $0.72(0.50-1.04)$ & $0.54(0.41-0.71)$ & $0.54(0.45-0.66)$ \\
\hline \multicolumn{7}{|l|}{ Stage } \\
\hline I & 1.00 & - & 1.00 & 1.00 & - & 1.00 \\
\hline II & $1.29(1.20-1.39)$ & - & $1.28(1.19-1.37)$ & $1.49(1.33-1.66)$ & - & $1.45(1.30-1.61)$ \\
\hline III & - & 1.00 & $1.52(1.42-1.63)$ & - & 1.00 & $1.86(1.67-2.08)$ \\
\hline IV & - & $1.20(1.13-1.28)$ & $1.83(1.73-1.93)$ & - & $1.19(1.09-1.31)$ & $2.21(2.03-2.40)$ \\
\hline Un-staged & - & - & $1.61(1.50-1.74)$ & - & - & $1.86(1.65-2.09)$ \\
\hline \multicolumn{7}{|l|}{ Lymph node site } \\
\hline Nodal & 1.00 & 1.00 & 1.00 & 1.00 & 1.00 & 1.00 \\
\hline Extranodal & $0.91(0.86-0.98)$ & $0.85(0.79-0.92)$ & $0.87(0.83-0.91)$ & $0.94(0.84-1.04)$ & $0.80(0.72-0.90)$ & $0.83(0.77-0.89)$ \\
\hline \multicolumn{7}{|l|}{ Comorbidity scores } \\
\hline 0 & 1.00 & 1.00 & 1.00 & 1.00 & 1.00 & 1.00 \\
\hline 1 & $1.35(1.25-1.46)$ & $1.26(1.18-1.35)$ & $1.31(1.25-1.37)$ & $1.23(1.09-1.39)$ & $1.21(1.10-1.330$ & $1.23(1.14-1.32)$ \\
\hline 2 & $1.59(1.44-1.75)$ & $1.60(1.46-1.74)$ & $1.62(1.52-1.72)$ & $1.42(1.21-1.67)$ & $1.37(1.20-1.56)$ & $1.44(1.31-1.58)$ \\
\hline$\geq 3$ & $2.44(2.19-2.72)$ & $1.86(1.69-2.05)$ & $2.08(1.94-2.22)$ & $2.11(1.78-2.510$ & $1.58(1.37-1.81)$ & $1.73(1.56-1.92)$ \\
\hline \multicolumn{7}{|l|}{ Therapy } \\
\hline None & 1.00 & 1.00 & 1.00 & 1.00 & 1.00 & 1.00 \\
\hline Radiation only & $0.80(0.72-0.88)$ & $1.11(0.98-1.26)$ & $0.87(0.81-0.94)$ & $0.81(0.69-0.960$ & $1.08(0.90-1.29)$ & $0.87(0.78-0.98)$ \\
\hline Chemotherapy only & $1.00(0.93-1.09)$ & $0.82(0.77-0.88)$ & $0.88(0.84-0.92)$ & $1.11(0.98-1.27)$ & $0.87(0.79-0.95)$ & $0.94(0.87-1.00)$ \\
\hline Both & $0.84(0.76-0.93)$ & $0.93(0.84-1.03)$ & $0.85(0.79-0.91)$ & $1.02(0.88-1.19)$ & $1.07(0.94-1.23)$ & $1.01(0.91-1.11)$ \\
\hline
\end{tabular}

Cancer. Author manuscript; available in PMC 2018 December 17. 


\begin{tabular}{|c|c|c|c|c|c|c|}
\hline \multirow{3}{*}{$\begin{array}{l}\text { Race/ethnicity and other } \\
\text { factors }\end{array}$} & \multicolumn{6}{|c|}{ Hazard ratio $\left(95 \%\right.$ confidence interval) of mortality ${ }^{\dagger}$} \\
\hline & \multicolumn{3}{|c|}{ All-cause mortality } & \multicolumn{3}{|c|}{ NH-Lymphoma-specific mortality } \\
\hline & Stage I-II & Stage III-IV & All stages & Stage I-II & Stage III-IV & All stages \\
\hline \multicolumn{7}{|l|}{ SES (quartile) ${ }^{\dagger}$} \\
\hline $1^{\text {st }}$ (high) & 1.00 & 1.00 & 1.00 & 1.00 & 1.00 & 1.00 \\
\hline $2^{\text {nd }}$ & $1.07(0.98-1.17)$ & $1.05(0.97-1.140$ & $1.04(0.98-1.10)$ & $1.07(0.92-1.24)$ & $1.05(0.94-1.190$ & $1.06(0.97-1.16)$ \\
\hline $3^{\text {rd }}$ & $1.12(1.02-1.23)$ & $1.16(1.06-1.26)$ & $1.13(1.07-1.20)$ & $1.10(0.94-1.280$ & $1.26(1.12-1.43)$ & $1.20(1.09-1.31)$ \\
\hline $4^{\text {th }}($ low $)$ & $1.31(1.19-1.44)$ & $1.22(1.12-1.33)$ & $1.23(1.16-1.31)$ & $1.22(1.04-1.43)$ & $1.17(1.03-1.33)$ & $1.18(1.08-1.30)$ \\
\hline $\begin{array}{l}* \text { Denotes significance level } \mathrm{p} \\
\mathrm{p}<0.01 \text {. }\end{array}$ & 0.05 & & & & & \\
\hline
\end{tabular}


Table 6.

All-cause and NH-Lymphoma-specific mortality in association with race/ethnicity, stratified by subtypes of NH-Lymphoma

\begin{tabular}{|c|c|c|c|c|}
\hline \multirow{2}{*}{$\begin{array}{l}\text { Race/ethnicity and other } \\
\text { factors }\end{array}$} & \multicolumn{4}{|c|}{ Hazard ratio ( $95 \%$ confidence interval) of mortality, ${ }^{*}$ by subtypes of NH-Lymphoma } \\
\hline & $\begin{array}{l}\text { Diffuse large B-cell } \\
\text { lymphoma(DLBCL) }\end{array}$ & $\begin{array}{l}\text { Chronic lymphocytic } \\
\text { leukemia or small } \\
\text { lymphocytic } \\
\text { lymphoma }\end{array}$ & Follicular lymphoma & $\begin{array}{c}\text { All other subtypes or } \\
\text { unknown }\end{array}$ \\
\hline \multicolumn{5}{|c|}{ All-cause mortality } \\
\hline \multicolumn{5}{|l|}{ Race/ethnicity } \\
\hline Caucasians & 1.00 & 1.00 & 1.00 & 1.00 \\
\hline African-Americans & $1.05(0.88-1.25)$ & $0.95(0.69-1.31)$ & $1.00(0.71-1.43)$ & $0.94(0.80-1.10)$ \\
\hline Others & $1.11(0.97-1.26)$ & $1.00(0.73-1.37)$ & $0.71(0.47-1.09)$ & $1.12(0.97-1.28)$ \\
\hline \multicolumn{5}{|l|}{ Sex } \\
\hline Male & 1.00 & 1.00 & 1.00 & 1.00 \\
\hline Female & $0.88(0.82-0.94)$ & $0.73(0.64-0.82)$ & $0.74(0.63-0.86)$ & $0.76(0.71-0.82)$ \\
\hline \multicolumn{5}{|l|}{ Age } \\
\hline $65-69$ & 1.00 & 1.00 & 1.00 & 1.00 \\
\hline $70-74$ & $1.19(1.07-1.32)$ & $1.43(1.20-1.70)$ & $1.53(1.20-1.96)$ & $1.19(1.07-1.32)$ \\
\hline $75-79$ & $1.43(1.29-1.58)$ & $1.85(1.54-2.21)$ & $1.77(1.38-2.26)$ & $1.55(1.40-1.72)$ \\
\hline 280 & $1.78(1.61-1.97)$ & $2.94(2.46-3.52)$ & $3.11(2.46-3.92)$ & $2.34(2.12-2.59)$ \\
\hline \multicolumn{5}{|l|}{ Marital status } \\
\hline Married & 1.00 & 1.00 & 1.00 & 1.00 \\
\hline Unmarried & $1.06(0.99-1.14)$ & $1.36(1.19-1.55)$ & $1.17(0.99-1.38)$ & $1.24(1.15-1.33)$ \\
\hline Unknown & $0.94(0.77-1.14)$ & $0.92(0.65-1.30)$ & $1.09(0.79-1.51)$ & $0.58(0.49-0.69)$ \\
\hline \multicolumn{5}{|c|}{ NH-Lymphoma-specific mortality } \\
\hline \multicolumn{5}{|l|}{ Race/ethnicity } \\
\hline Caucasians & 1.00 & 1.00 & 1.00 & 1.00 \\
\hline African-Americans & $1.19(0.95-1.50)$ & $1.00(0.59-1.69)$ & $0.70(0.33-1.49)$ & $1.04(0.82-1.33)$ \\
\hline Others & $1.14(0.95-1.37)$ & $0.87(0.51-1.48)$ & $0.79(0.33-1.91)$ & $1.15(0.92-1.43)$ \\
\hline \multicolumn{5}{|l|}{ Sex } \\
\hline Male & 1.00 & 1.00 & 1.00 & 1.00 \\
\hline Female & $0.92(0.84-1.02)$ & $0.76(0.62-0.95)$ & $0.77(0.57-1.05)$ & $0.91(0.82-1.02)$ \\
\hline \multicolumn{5}{|l|}{ Age } \\
\hline $65-69$ & 1.00 & 1.00 & 1.00 & 1.00 \\
\hline $70-74$ & $1.16(1.01-1.33)$ & $1.20(0.91-1.59)$ & $1.67(0.99-2.79)$ & $1.23(1.04-1.45)$ \\
\hline $75-79$ & $1.32(1.15-1.52)$ & $1.36(1.01-1.84)$ & $2.44(1.48-4.02)$ & $1.42(1.20-1.67)$ \\
\hline$\geq 80$ & $1.38(1.20-1.58)$ & $2.31(1.73-3.09)$ & $4.28(2.66-6.89)$ & $2.12(1.81-2.48)$ \\
\hline \multicolumn{5}{|l|}{ Marital status } \\
\hline Married & 1.00 & 1.00 & 1.00 & 1.00 \\
\hline Unmarried & $1.09(0.99-1.21)$ & $1.25(1.00-1.56)$ & $1.13(0.82-1.55)$ & $1.19(1.06-1.34)$ \\
\hline Unknown & $0.80(0.59-1.08)$ & $0.67(0.34-1.32)$ & $0.54(0.26-1.15)$ & $0.44(0.32-0.60)$ \\
\hline
\end{tabular}


* SES denotes socioeconomic status. Hazard ratio adjusted for variables listed in the tables plus tumor stage, lymph node site, comorbidity score, therapy, socioeconomic status, the year of diagnosis and SEER areas. 